\title{
Vortex suppression of the tip leakage flow over a NACA0009 hydrofoil via a passive jet induced by the double-control-hole
}

Citation for published version (APA):

Huang, Y., Zhang, D., Wang, F., Zhang, G., \& van Esch, B. P. M. (2021). Vortex suppression of the tip leakage flow over a NACA0009 hydrofoil via a passive jet induced by the double-control-hole. Ocean Engineering, 237, [109647]. https://doi.org/10.1016/j.oceaneng.2021.109647

\section{Document license: \\ TAVERNE}

DOI:

10.1016/j.oceaneng.2021.109647

Document status and date:

Published: 01/10/2021

\section{Document Version:}

Publisher's PDF, also known as Version of Record (includes final page, issue and volume numbers)

\section{Please check the document version of this publication:}

- A submitted manuscript is the version of the article upon submission and before peer-review. There can be important differences between the submitted version and the official published version of record. People interested in the research are advised to contact the author for the final version of the publication, or visit the $\mathrm{DOI}$ to the publisher's website.

- The final author version and the galley proof are versions of the publication after peer review.

- The final published version features the final layout of the paper including the volume, issue and page numbers.

Link to publication

\section{General rights}

Copyright and moral rights for the publications made accessible in the public portal are retained by the authors and/or other copyright owners and it is a condition of accessing publications that users recognise and abide by the legal requirements associated with these rights.

- Users may download and print one copy of any publication from the public portal for the purpose of private study or research.

- You may not further distribute the material or use it for any profit-making activity or commercial gain

- You may freely distribute the URL identifying the publication in the public portal.

If the publication is distributed under the terms of Article 25fa of the Dutch Copyright Act, indicated by the "Taverne" license above, please follow below link for the End User Agreement:

www.tue.nl/taverne

Take down policy

If you believe that this document breaches copyright please contact us at:

openaccess@tue.nl

providing details and we will investigate your claim. 


\title{
Vortex suppression of the tip leakage flow over a NACA0009 hydrofoil via a passive jet induced by the double-control-hole
}

\author{
Yadong Huang $^{\mathrm{a}}$, Desheng Zhang ${ }^{\mathrm{a},{ }^{*}}$, Fei Wang ${ }^{\mathrm{a}}$, Guangjian Zhang ${ }^{\mathrm{a}}$, B.P.M. (Bart) van Esch ${ }^{\mathrm{b}}$ \\ ${ }^{a}$ Research Center of Fluid Machinery Engineering and Technology, Jiangsu University, Zhenjiang, 212013, China \\ ${ }^{\mathrm{b}}$ Department of Mechanical Engineering, Eindhoven University of Technology, Eindhoven, 5600MB, the Netherlands
}

\section{A R T I C L E I N F O}

\section{Keywords:}

Tip leakage vortex suppression

Passive jet

DC hole

NACA0009 hydrofoil

\begin{abstract}
A B S T R A C T
Tip leakage vortex (TLV) frequently occurring in bladed energy conversion machines may induce flow loss as well as cavitation. The double-curved-hole (DC hole) structures located at the $10 \%-25 \%$ chord near the leading edge of the foil are adopted to induce a passive jet thus suppressing the tip leakage vortex structures in this paper. The control effects and the control mechanisms of three DC hole positions are illustrated by numerical analyses based on the rotation-curvature corrected shear stress transport (SST) $k-\omega$ turbulence model and the ZwartGerber-Belamri (ZGB) cavitation model. The results demonstrate that the passive jet from the DC hole could divide the TLV into several parts and induce new vortical structures. The newborn vortical structures can be classified into three types: weakened tip leakage vortex (WTLV), newborn secondary tip leakage vortex (NSTLV) and hole separation vortex (HSV). The control effects for different tip clearance are greatly related to the DC hole location. Once the DC hole locates near the merger point of the tip leakage vortex and the tip separation vortex, it could achieve the best control effects. Besides, TLV core pressure could be improved thus suppressing the local cavitation, and the lift-drag ratio for different inlet velocities can be slightly reduced.
\end{abstract}

\section{Introduction}

Ocean hydropower is one of the most reliable and sustainable energy sources in the world. The energy performance is closely related to the flow characteristics of hydraulic machinery (Li et al., 2017; Luo et al., 2015; Prasad et al., 2014). The gap between the rotor and the stator is inevitable, such as in compressors, turbines and pumps. The tip leakage vortex (TLV) and tip separation vortex (TSV) that appear in the tip region could cause energy loss, noise, and cavitation phenomenon (Xiao et al., 2001; Gopalan et al., 2002; Zhang et al., 2015a). Many studies have demonstrated that the gap size has a crucial effect on the TLV, and the efficiency declines obviously with increasing gap size in hydraulic machinery (Kim and Chun, 2007; Yu et al., 2019). Meanwhile, the size and strength of TLV increase with the gap size (You et al., 2006; Pogorelov et al., 2016; Decaix et al., 2015). Therefore, researchers have performed numerous experimental and numerical investigations of the evolution of TLV as well as the flow mechanism in the gap region (Liu et al., 2020; Xi et al., 2021). Decaix et al., 2015, 2016, 2018 captured the flow trajectory of TLV around a hydrofoil with tip clearance, using the shear stress transport (SST) $k$ - $\omega$ model (Menter, 2009). They found cavitation could make the TLV trajectory closer to the suction side compared with the non-cavitation case and cause a misalignment between the high vorticity region and the cavitating region. Smirnov and Menter (2009) developed a SST-CC model by adding a rotation-curvature correction (CC) term into the original SST $k$ - $\omega$ model. The improved model was proven to be able to enhance the prediction accurateness of the TLV evolution (Arolla and Durbin, 2014; Guo et al., 2018). In consideration of the influence of the angular momentum on the vortex cavitation, the modified cavitation model is used to investigate the TLV cavitation (Guo et al., 2019; Zhao et al., 2016). Dreyer et al., 2014a, 2014b experimentally investigated the flow mechanism and flow pattern of TLV cavitation around a hydrofoil, considering the influences of different attack angles, gap sizes, and inlet velocity. Their results illustrated the smaller clearance could pull the TLV away from the hydrofoil more, and TLV cavitation could alter the vortex trajectory as well as the wandering amplitude. The effects of TLV on different cavitation patterns have been analyzed, such as horseshoe vortex cavitation, sheet cavitation, tip separation vortex cavitation, and perpendicular cavitation vortex (PCV) (Ji et al., 2013; Bai et al., 2018; Cheng et al., 2019, 2020). It is suggested that TLV interact with the mainstream at the trailing edge of the blade to form PCV (Tan et al., 2015; Zhang et al., 2015b).

\footnotetext{
* Corresponding author.

E-mail address: zds@ujs.edu.cn (D. Zhang).
} 
As the TLV could cause negative influence on the system efficiency and the flow stability of the hydraulic machinery, it is urgent to control and suppress TLV and the associated TLV cavitation. Fortunately, some efforts have been done to suppress the TLV as well as its cavitation. We know the control method are usually divided into two types: active and passive methods (Souri and Mojra, 2021). As the TLV always start around $20-30 \%$ chord close to the suction side of the blade tip (Wu et al., 2011), there are few available places to place the control actuator. So, researchers commonly adopt the passive control methods. Chang et al. (2011) proposed tip vortex cavitation suppression by active mass injection. Their results showed that the optimal levels of mass injection reduced the inception cavitation number from 3.5 to 1.9 (a reduction of 45\%). Timoshevskiy et al. (2018) experimentally investigated the method of manipulating cavitation by a wall jet on a 2D hydrofoil. and they found that the wall jet can effectively manipulate cavitation. Liu and Tan, 2018, 2020a suggested the method of C groove in the tip to suppress vortex and cavitation for a hydrofoil, The $\mathrm{C}$ groove is close to the leading edge of the tip, and the exit of $\mathrm{C}$ groove is nearly perpendicularly to the primary TLV. and they found the $\mathrm{C}$ groove can decrease the vortex area under all geometric conditions. Amini et al. (2019) observed in their experiment that the maximum tangential velocity of the tip vortex falls to almost half of the baseline and the vortex core size increases significantly (by almost 70\%) for the most effective winglet in the tip. These effects are accompanied by a visible reduction in the axial velocity at the vortex core leading to further mitigation of tip vortex cavitation. Fei et al.'s (Fei et al., 2019) numerical results showed that the groove could affect the tip leakage vortex cavitating flow. The groove enhances the interaction between the tip leakage flow and main flow, and then it affects the cavitation of the tip leakage vortex. Guo et al. (2016) numerically investigated the effect of round tip and sharp tip on the flow field and performance of a hydrofoil. In addition, a novel method of $\mathrm{T}$ shape tip is proposed to improve energy performance and suppress TLV, the results showed that the T shape tip remarkably suppresses the flow separation around the pressure side tip corner and decreases the pressure gradient and reduce the TLV area in the tip (Lei et al., 2017; Liu and Tan, 2020b).

From the above, the methods of TLV suppression need further researches. The objective of this paper is to put forward a new strategy on TLV suppression. Referring to the experiment of Dreyer et al. (2014b), a double-curved-hole (DC hole) structure is proposed to suppress the TLV. The vortical structures, dynamic performance of the foil as well as the control mechanism will be discussed in detail in this paper.

\section{Methology}

\subsection{Physical model}

Fig. 1 shows the schematic diagram of the computational domain which is referred to the experiment of Dreyer et al., 2014a, 2014b. The NACA0009 hydrofoil is chosen as the object of which the chord is $C=$ $100 \mathrm{~mm}$, and the span is $b=146-148 \mathrm{~mm}$, with the maximum thickness

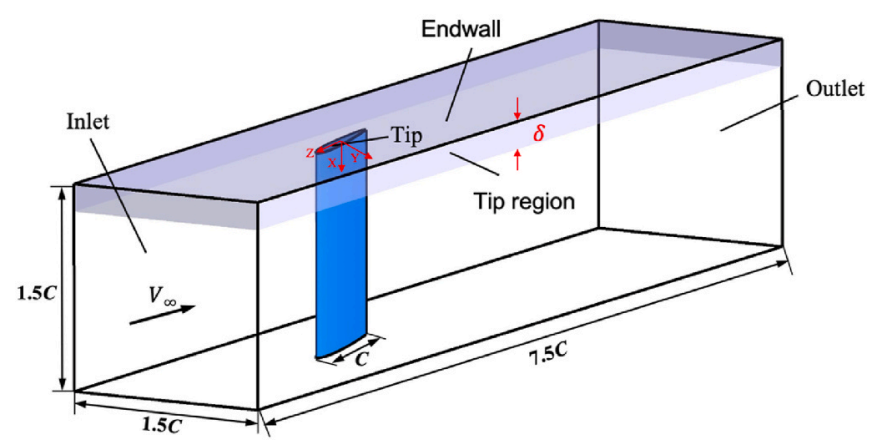

Fig. 1. Computational model. $h=9.9 \mathrm{~mm}$. The length of the flow channel is $7.5 C$, and the width is 1.5C. The tip clearance size $\delta$ is normalized by $h$, leading to a non-dimensional variable $\tau=\delta / h$. Three typical conditions with $\tau=0.2$, $\tau=0.3$, and $\tau=0.4$ will be discussed in this paper.

As shown in Fig. 2, the DC hole (a combined structure of two holes) is close to the leading edge (LE) of the foil. The passive jet induced by the pressure difference between the pressure side (PS) and the suction side (SS), could interact with the TLV, thus modifying the TLV structures as well as the pressure. The distance of the DC hole from the top surface of the foil tip is $1 \mathrm{~mm}$, and the height of the hole is $2 \mathrm{~mm}$. From the inlet to the outlet of the DC hole, it gradually contracts, thereby causing an increase in the velocity of the jet flow. The hole closer to the leading edge is named $\mathrm{H} 1$, and the adjacent one is named $\mathrm{H} 2$. The detailed geometry parameters of the hole is shown in Fig. 2 (b). The points labelled A, B, C, $\mathrm{D}$ and $\mathrm{E}$ are on the foil chord ( $\mathrm{AB}=\mathrm{CD}=2 \mathrm{~mm}, \mathrm{BC}=3 \mathrm{~mm})$, and the point $\mathrm{E}$ is located at the foil leading edge. The length of $L_{A E}$ is used to control the position of the DC hole. Once $L_{A E}$ is determined, the position of the DC hole is determined. The side outline of the DC hole is formed by a B-spline curve. M0 is the original case, means no control. M1, M2, and M3 are the different position schemes. The three model schemes and the DC hole geometry parameters are shown in Table 1.

\subsection{Numerical method}

A commercial CFD code of ANSYS CFX is used in present work with a RANS solver. In the following steady-state equations, the bar is dropped for averaged quantities, except for products of fluctuating quantities.

$\frac{\partial \rho}{\partial t}+\frac{\partial}{\partial x_{j}}\left(\rho u_{j}\right)=0$

$\frac{\partial}{\partial t}\left(\rho u_{i}\right)+\frac{\partial}{\partial x_{j}}\left(\rho u_{i} u_{j}\right)=-\frac{\partial p}{\partial x_{i}}+\frac{\partial}{\partial x_{j}}\left(\mu \frac{\partial u_{i}}{\partial x_{j}}-\rho \overline{u_{i}^{\prime} u_{j}^{\prime}}\right)+S_{M}$

where $u i(i=u, v, w)$ is the velocity, $x i(i=x, y, z)$ is the position, $t$ is the time, $p$ is the pressure, $\mu$ is the dynamic viscosity, $S_{M}$ is the external momentum source term. The Reynolds stresses $\rho \overline{u_{i}^{\prime} u_{j}^{\prime}}$ can be modified by a turbulence model. For the multiphase flow, the homogeneous (onefluid) model allows some simplifications with an assumption that the transported quantities are the same for all phases, except for the volume fraction $\alpha . \rho$ is defined as the density of mixture with the following definition:

$\rho=\alpha_{v} \rho_{v}+\alpha_{l} \rho_{l}$

where the subscripts $v$ and $l$ represent the vapor and liquid phases respectively.

In order to accurately capture the flow trajectory around the tip clearance, the SST $k$ - $\omega$ model is determined as the turbulence model in the present simulation. It has a good adaptability to the simulation of flow separation (Zarei et al., 2020). The SST $k$ - $\omega$ model with a rotation-curvature correction (SST-CC) (Smirnov and Menter, 2009) is used in the current calculation owing to the rotation characteristics and curvature factors around the TLV. The SST-CC model improves the prediction of the velocity in TLV on the measured sections in downstream, and gives a good prediction of the vorticity and pressure characteristics of the TLV trajectory (Guo et al., 2018). The ZGB cavitation model (Cheng et al., 2019) is used to simulate the flow with cavitation. According to the experiments previously conducted by Dreyer et al. (2014b), the inlet velocity is set as a normal speed with low turbulence intensity, and an adjustable static pressure is used as the outlet boundary to ensure the inlet pressure $p_{\infty}$ maintains at 1 bar. Additionally, for the enclosing walls, no slip and smooth walls are assumed as boundary conditions. The high-resolution scheme is selected for the advection scheme and turbulence numeric. The convergence criterion is set to root-mean-square residuals of $10^{-7}$ for non-cavitation and $10^{-5}$ for 


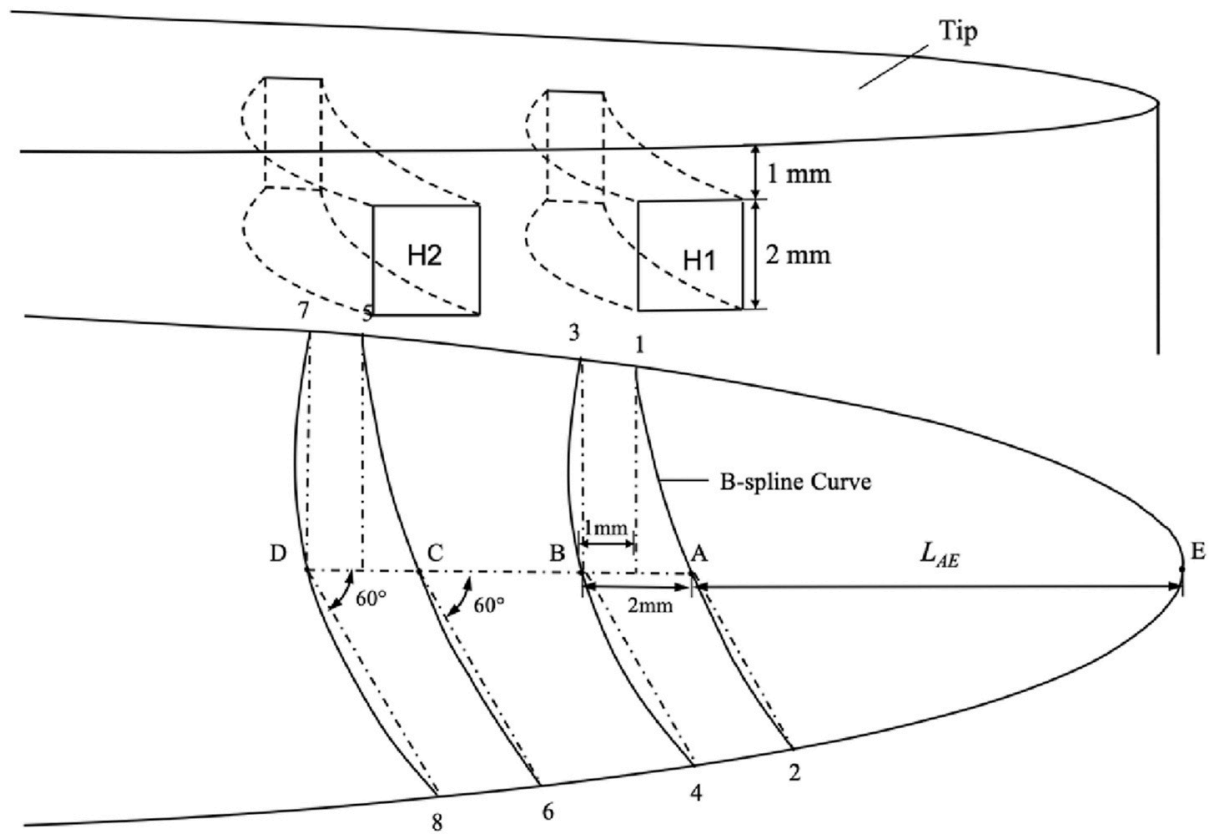

Fig. 2. Structure of the DC hole.

Table 1

Parameters of the optimization schemes.

\begin{tabular}{llllll}
\hline Case & $L_{A E}$ & $\angle E A 2=\angle A B 4$ & $\angle B C 6=\angle C D 8$ & $\angle A B 3=\angle C D 7$ & $\mathrm{BC}$ \\
\hline M1 & $10 \mathrm{~mm}$ & $60^{\circ}$ & $60^{\circ}$ & $90^{\circ}$ & $3 \mathrm{~mm}$ \\
M2 & $15 \mathrm{~mm}$ & $60^{\circ}$ & $60^{\circ}$ & $90^{\circ}$ & $3 \mathrm{~mm}$ \\
M3 & $20 \mathrm{~mm}$ & $60^{\circ}$ & $60^{\circ}$ & $90^{\circ}$ & $3 \mathrm{~mm}$ \\
\hline
\end{tabular}

cavitation.

\section{Mesh and validation}

A structured hexahedral mesh is generated in the present case as shown in Fig. 3. The O-type topology and local mesh refinement are adopted because the O-type topology can generate the body-fitted grid as well as the ideal boundary layer mesh. Besides, different nodes are arranged from the foil tip to the endwall according to the tip gap size. In the case of DC hole, the mesh in the hole is also refined to capture the flow details. The mesh quality is appropriate with the value quality criterion beyond 0.67 in the ANSYS ICEM CFD. The average value of Y+
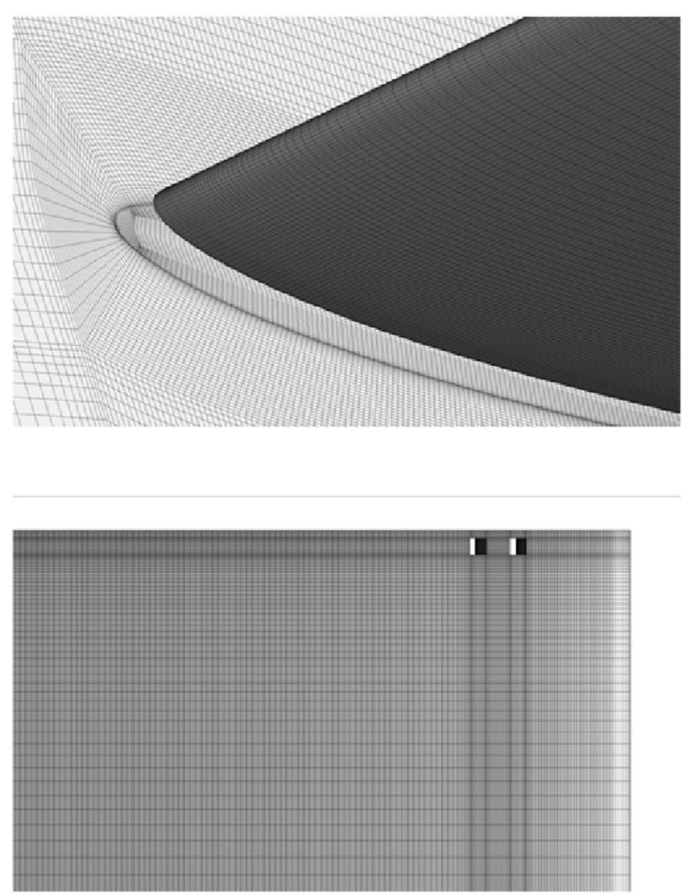

Fig. 3. Computational domain mesh. 
on the foil surface is mainly in the range of 10-20. The total number of mesh elements is 5.8-7.8 millions, referring to the mesh independency validation of Guo et al., 2016, 2018.

In order to verify the reliability of numerical results, some specific numerical parameters are compared to existing experiments conducted by Dreyer et al. (2014b), the inlet velocity is $10 \mathrm{~m} / \mathrm{s}$, and the incidence angle is $10^{\circ}$ in the case of the tip clearance $\tau=0.2$. The TSV and TLV trajectory is compared between the experimental result and simulated cavitation structure (vapor volume fraction $\alpha=0.1$ ), as shown in the Fig. 4. The numerical results of TLV structure are in qualitatively good agreement with the experimental results. Moreover, the axial velocity contours and the circumferential velocity contours of the $x-y$ section at the same spatial position are similar with those obtained in the experiment. The above comparison shows the accuracy and validity of the numerical results.

\section{Results and discussion}

\subsection{Vortical structures}

The TLV structures for different control schemes with different tip clearances are shown in Fig. 5. The vortices are visualized via $Q$ criterion which is the second invariant of the velocity gradient tensor $(Q=$ $\left.\frac{1}{2}\left((\nabla \cdot V)^{2}-\operatorname{tr}\left(\nabla V^{2}\right)\right)\right)$. The TLV structures under no control are shown in Fig. 5(a). It could be found the starting point of the TLV locates at about $10 \%$ of chord length from the leading edge, and the initial position of the TLV gradually shifts downstream with the increasing clearance. The tip separation vortex and the tip leakage vortex could merge together and the merger location moves downstream the foil leading edge as the clearance is increased. Besides, the swirling strength of the TLV also increases with the clearance according to the flow pattern. Fig. 5(b) (d) show the TLV structures for different control schemes. It could be obviously seen that three DC hole schemes have fine inhibitory effects on TLV. Some special structures exist in the DC hole, and these structures could be considered as the passive jet driven by the pressure difference between the pressure and suction sides. The passive jet from the DC hole interacts with the tip leakage flow thus breaking the amalgamation of the TLV and the TSV, inducing new vortical structures, dividing the TLV into several new vortical structures and suppressing the evolution of TLV.

As the passive jet impinges perpendicularly on the TLV, the TLV is divided into weakened TLV (WTLV), newborn secondary tip leakage vortex (NSTLV) and hole separation vortex (HSV). In addition, WTLV and NSTLV have an intersection at a downstream position. Compared

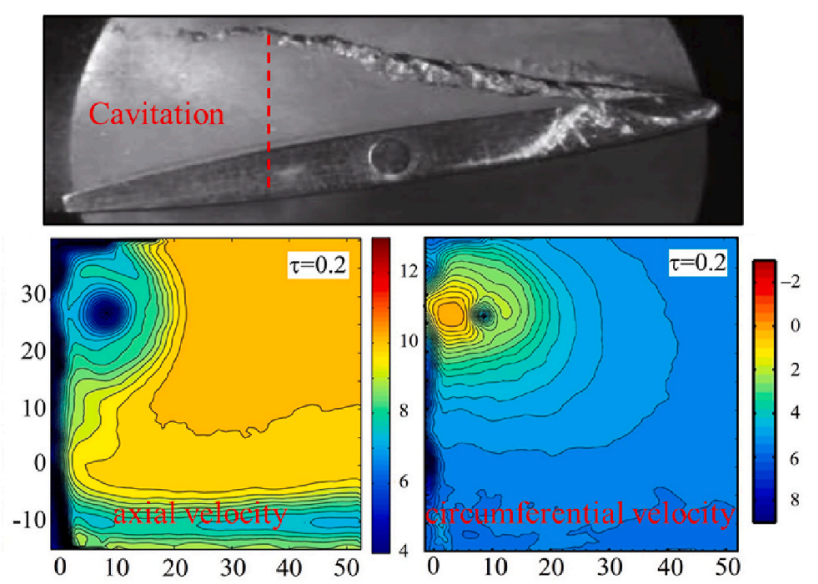

(a) experimental results[23] the flow patterns with each other, it could be found M1 scheme has the best effects for $\tau=0.2$ while M2 scheme and M3 schemes have the best effects for $\tau=0.3$ and $\tau=0.4$ respectively. Obviously, the location of the jet hole is the key factor in TLV suppression. Once the DC hole locates near the amalgamation position of the TLV and TSV, the passive jet not only inhibits the merger of TLV and TSV but also separate the TLV into WTLV and NSTLV.

\subsection{Streamline}

Fig. 6 shows the three dimensional streamlines starting from foil tip for $\tau=0.2-0.4$. For the original case M0 (Fig. 6(a)), the streamline structure of TLV is very strong and clear. For $\tau=0.2$, the initial position of TLV is at $10 \%$ of the chord, and TLV develops with strong velocity swirling strength above the suction side. In the range of $10 \%-60 \%$ of the chord length, the TLV's velocity swirling strength is so high, and the vortex streamline is straight and stable. When the TLV develops into the downstream region, the velocity swirling strength is slightly reduced, and the leakage flow from the gap is involved in the TLV. The streamlines for $\tau=0.3$ and 0.4 are similar with $\tau=0.2$.

Fig. 6 (b) (d) show that the passive jet induced by the DC hole could significantly suppresses the entrainment process. The velocity swirling strength has been significantly reduced compared to M0 owing to the passive jet. The vortex streamlines become deformed and unstable. Approximately in the middle of the chord length, the shape and the structure of the vortex change significantly. The radius of the vortex core becomes larger, but the velocity swirling strength has a prominent decrease. As discussed above, the position of the DC hole has an important influence on the vortex streamline. We can obviously see the M1 scheme is better than the other two schemes for $\tau=0.2$. As the gap increases, the streamline structure becomes more stable and its strength increases. The initial point of the vortex gradually moves downstream. Therefore, the more downstream DC hole solutions in M2 and M3 have a better performance. In short, compared with the original scheme, the DC hole scheme can suppress TLV.

\subsection{Lift and drag}

Table 2 shows the lift coefficient $C_{L}$ of the foil for $\tau=0.2$ and 0.4 . We could observe the lift coefficient for $\tau=0.2$ is larger than that for $\tau=0.4$ for the same control scheme. This phenomenon is attributed to the more energy loss for the larger tip clearance. For each tip clearance, the lift coefficient always decays with the DC hole moving downstream the leading edge. This is ascribed to the pressure loss for the passive jet, and this cause may be discussed in following sections.

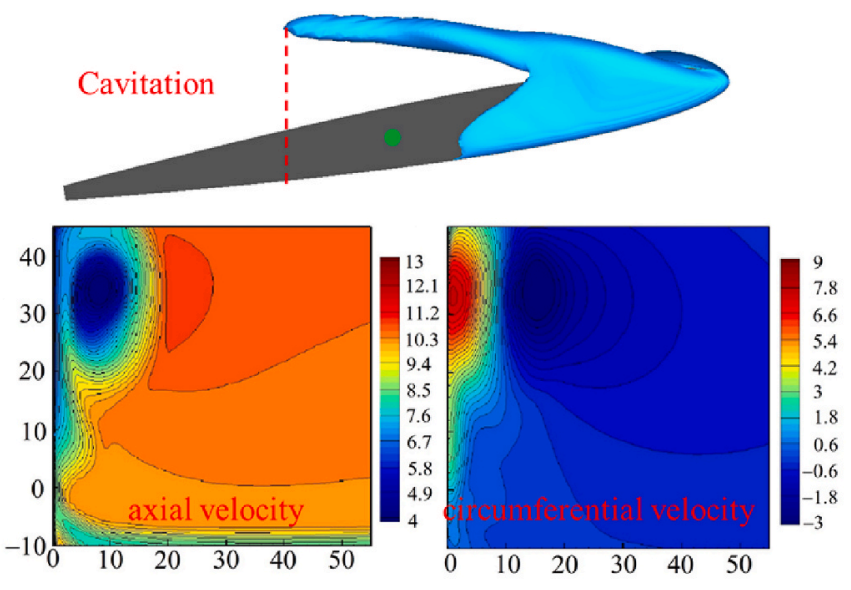

(b) current numerical results

Fig. 4. Comparison of TLV trajectory between experiment and numerical results $\left(V_{\infty}=10 \mathrm{~m} / \mathrm{s}\right)$. 

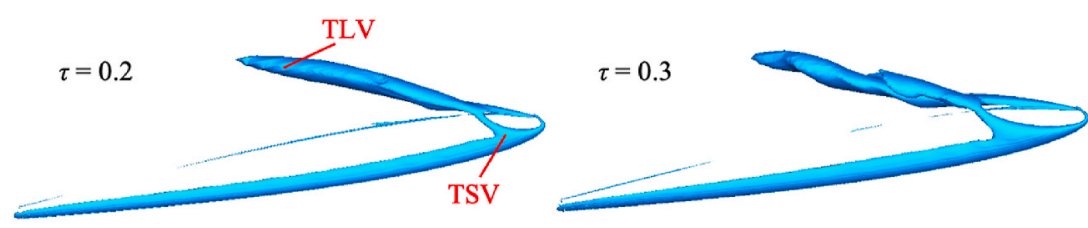

(a) M0
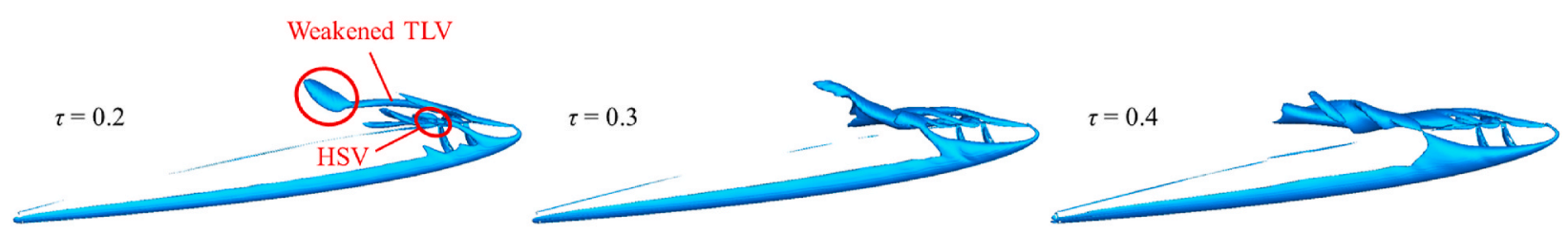

(b) M1
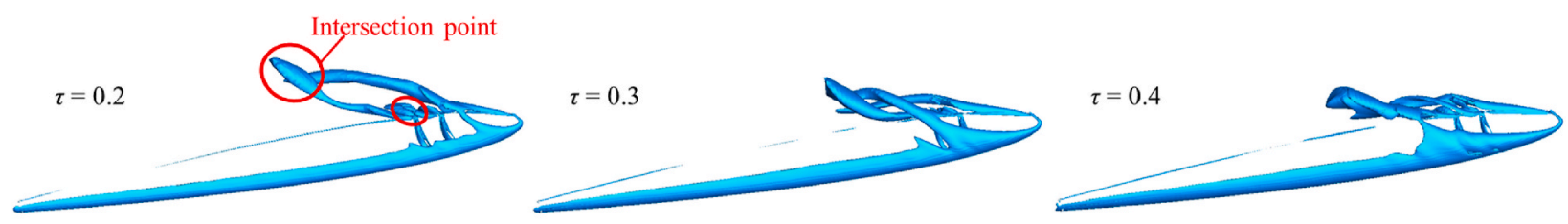

(c) $\mathrm{M} 2$
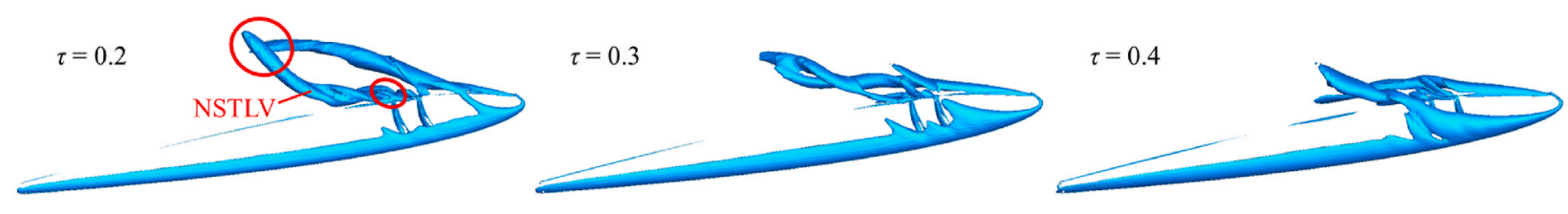

(d) M3
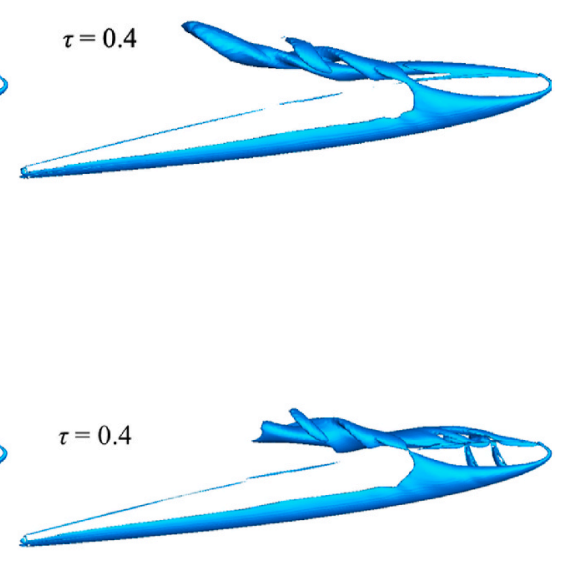

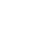



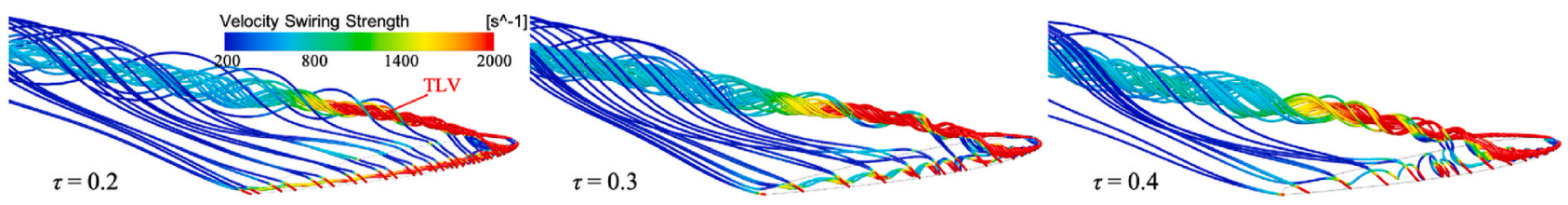

(a) M0
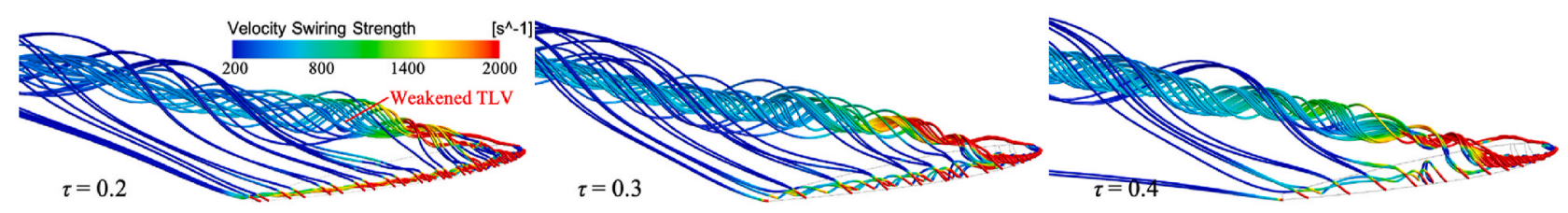

(b) M1
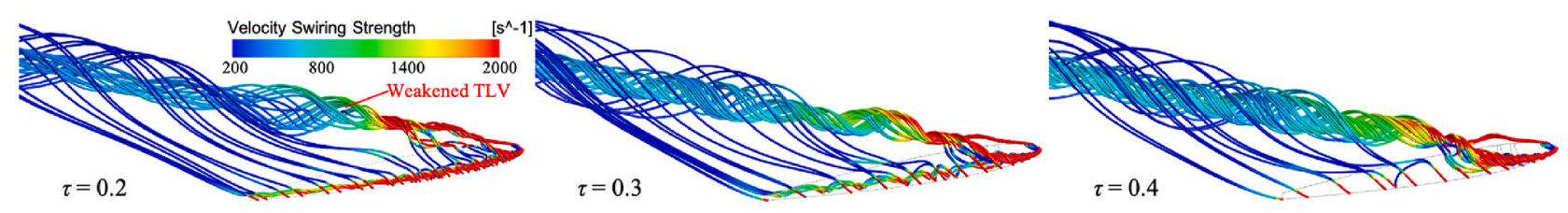

(c) M2
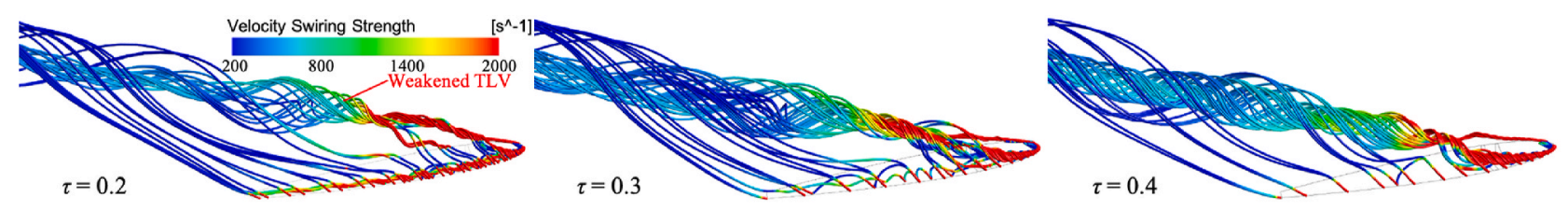

(d) M3

Fig. 6. Three dimensional streamlines contoured by velocity swirling strength under different conditions $\left(V_{\infty}=10 \mathrm{~m} / \mathrm{s}\right)$.

Table 2

Lift coefficient for different schemes $\left(V_{\infty}=10 \mathrm{~m} / \mathrm{s}\right)$.

\begin{tabular}{lll}
\hline Case & $C_{L}$ & \\
\cline { 2 - 3 } & $\tau=0.2$ & $\tau=0.4$ \\
\hline M0 & 1.2528 & 1.2154 \\
M1 & 1.2483 & 1.2142 \\
M2 & 1.2481 & 1.2103 \\
M3 & 1.2458 & 1.2091 \\
\hline
\end{tabular}

Meanwhile, the velocity magnitude in hole $\mathrm{H} 2$ is larger than that in hole H1. Although the jet rushes perpendicularly to the TLV, the flow direction could be modified by the upstream flow. So, local flow separations could occur near the hole thus leading to the HSVs. Besides, the low pressure in HSV could cause the pressure difference between the two holes, so part jet fluid of hole $\mathrm{H} 2$ flows towards hole H1. It could be clearly observed that there exists several low pressure regions downstream hole H2. This demonstrates that flow separation of the passive jet in hole $\mathrm{H} 2$ could separate the TLV into several parts. Combined action of the two holes could cause a stronger breaking power. In addition, as DC hole in M1 scheme is closer to the merger point of TLV and TSV, the control effects of M1 scheme are the best among the three control schemes.

Fig. 11(b) and (c) show the pressure and velocity vector distributions for $\tau=0.3, \tau=0.4$. The distribution features are analogue to those for $\tau$ $=0.2$. It can be seen that the location of the DC hole is a crucial factor in the control effects for different tip gaps. For $\tau=0.3$, the M2 scheme has the best control effect, while the M3 scheme is the best choice for $\tau=0.4$. As discussed above, once the DC hole locates near the merger point of TLV and TSV, separation of the passive jet could separate the TSV into several NSTLVs, and weaken TSV.

\section{Conclusion}

In the present research, a DC hole method is proposed to suppress the TLV of a hydrofoil with a tip clearance. The control effects for several geometric and flow parameters including hole position, tip clearance size, and inlet velocity are systematically investigated. The passive jet from the DC hole can perpendicularly impinge on the TLV, and divide the TLV inte sereral parts. The control effects are greatly related to the location of the DC hole for different tip clearance. The main conclusions can be drawn as follows:

(1) The DC hole method can successfully suppress the development of TLV and weaken the TLV. There are newborn vortexes around the DC hole, which can be classified into three types: weakened tip leakage vortex (WTLV), newborn secondary tip leakage vortex (NSTLV) above suction side downstream hole and hole separation vortex (HSV) in tip hole outlet. Besides, the velocity swirling strength has been significantly reduced, and the vortex streamlines become deformed and unstable under control of the DC hole.

(2) The DC hole method could greatly improve the TLV pressure distribution at the leading edge of the blade tip, inhibiting the development of the vortex core low pressure zone, and increases 


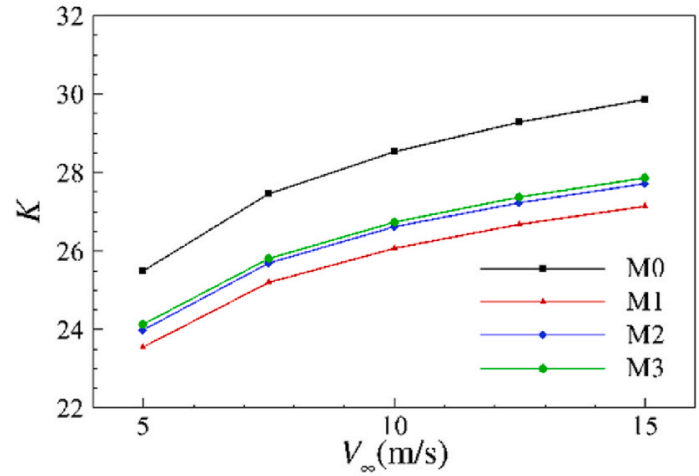

(a) $\tau=0.2$

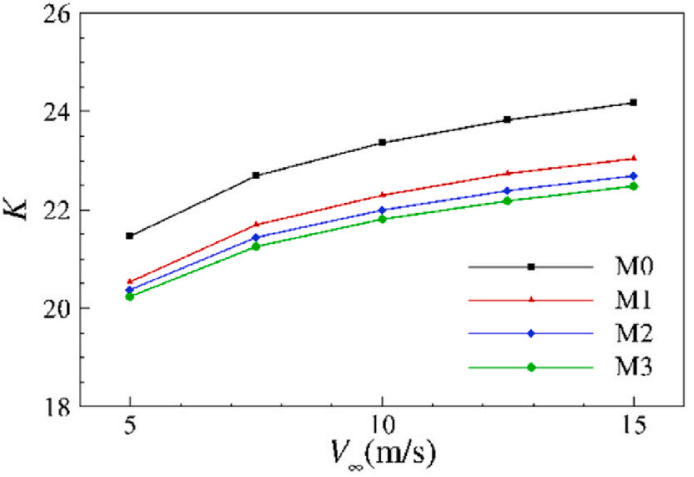

(b) $\tau=0.4$

Fig. 7. Variations of lift-drag ratio $K$ with the inlet velocity.

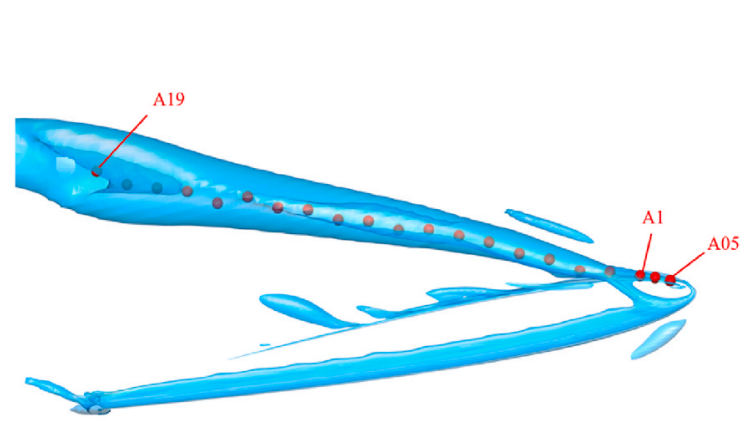

(a) Position.

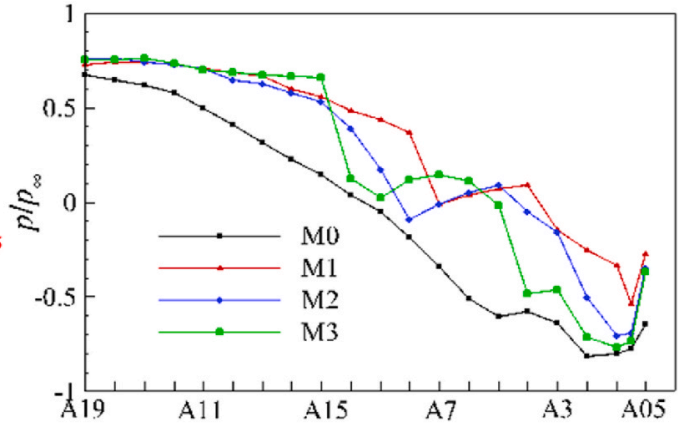

(b) Pressure

Fig. 8. Pressure along the TLV trajectory for different control schemes $\left(V_{\infty}=10 \mathrm{~m} / \mathrm{s}\right)$.

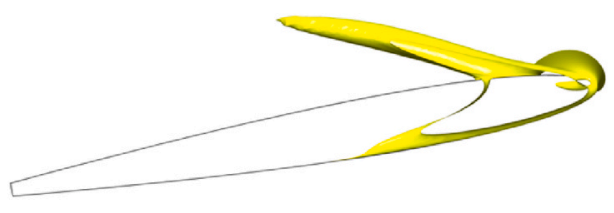

(a) MO

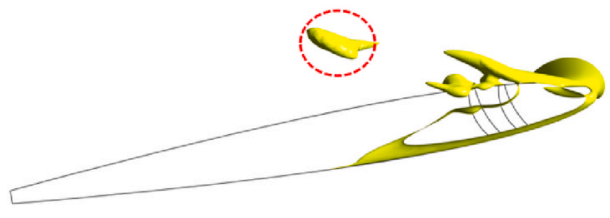

(c) M2

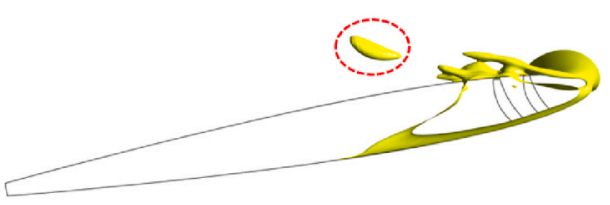

(b) M1

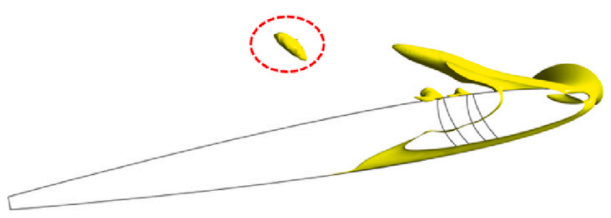

(d) M4

Fig. 9. Perssure defined by iso-surface of $3574 \mathrm{~Pa}$ for different schemes under condition of $\tau=0.2\left(V_{\infty}=10 \mathrm{~m} / \mathrm{s}\right)$.

the maximum vortex core pressure. As a result, local cavitation can be suppressed.

(3) The hole position has the most powerful impact on the control effects. Once the DC hole locates near the merger point of TLV and TSV, the DC hole could achieve the best control effects. Among the three control schemes, M1 scheme could achieve the best control effects for $\tau=0.2$ while M3 scheme is the best for $\tau=$ 0.4 .
(4) Under different inlet velocities, the lift coefficient and the lift drag ratio of the foil are slightly reduced. But if the DC hole can effectively suppress TLV, as well as the cavitation and noise it brings, and improve the stability of the flow, it provides a solution for engineering design.

The present work has shown the advantage of the proposed DC hole method on TLV suppression and vortex pressure improvement under different conditions. However, there are still further geometric 


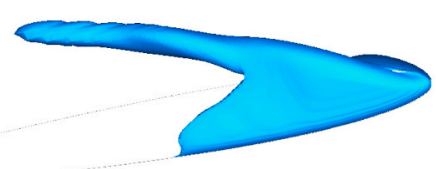

(a) $\mathrm{MO}$

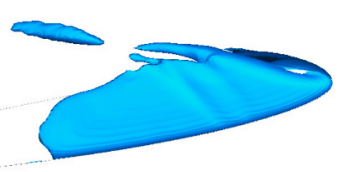

(c) $\mathrm{M} 2$

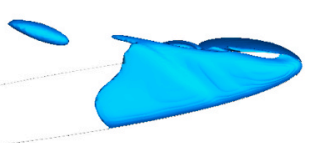

(b) M1

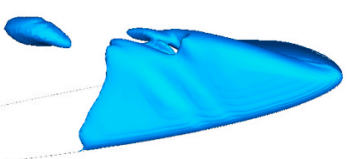

(d) M4

Fig. 10. Cavitation around the foils for different DC hole positions, vapor volume fraction $\alpha=0.1\left(V_{\infty}=10 \mathrm{~m} / \mathrm{s}\right)$.
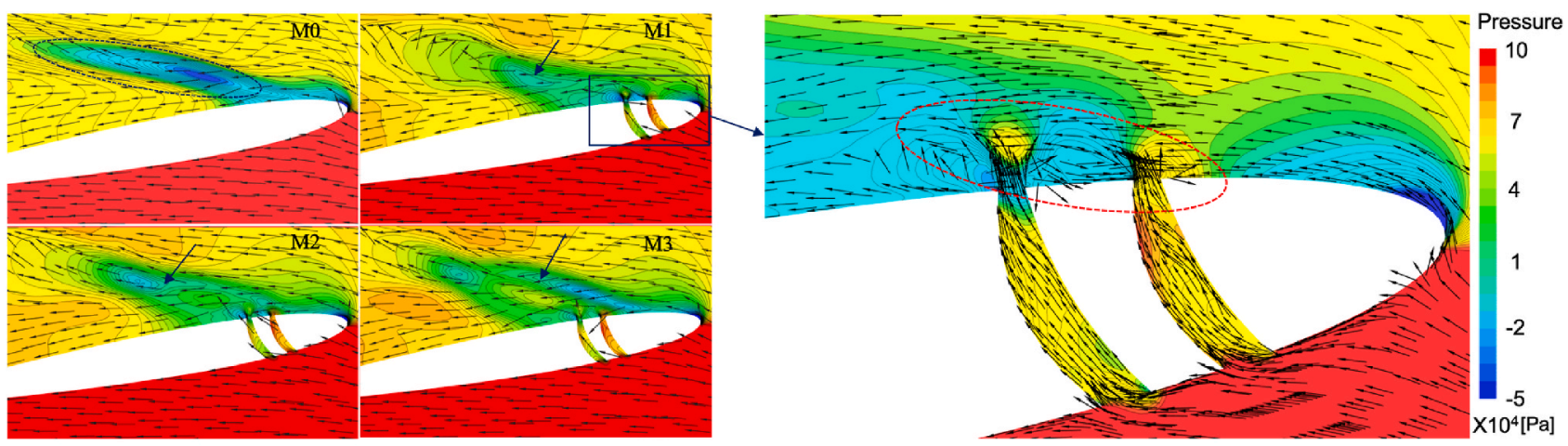

(a) $\tau=0.2$

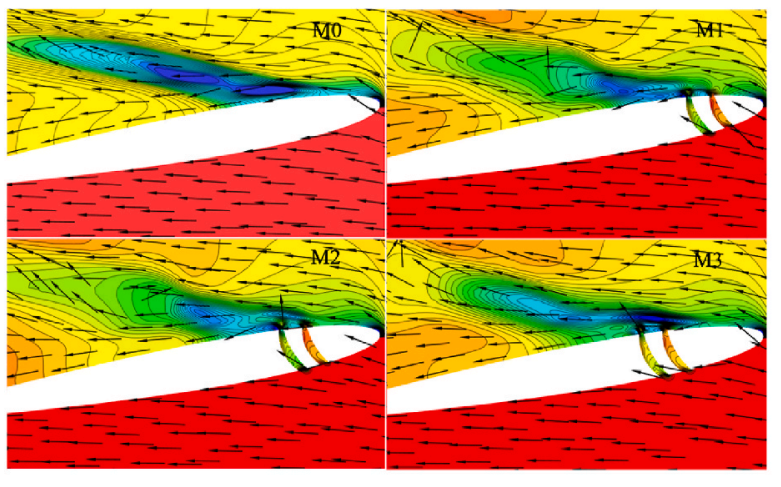

(b) $\tau=0.3$

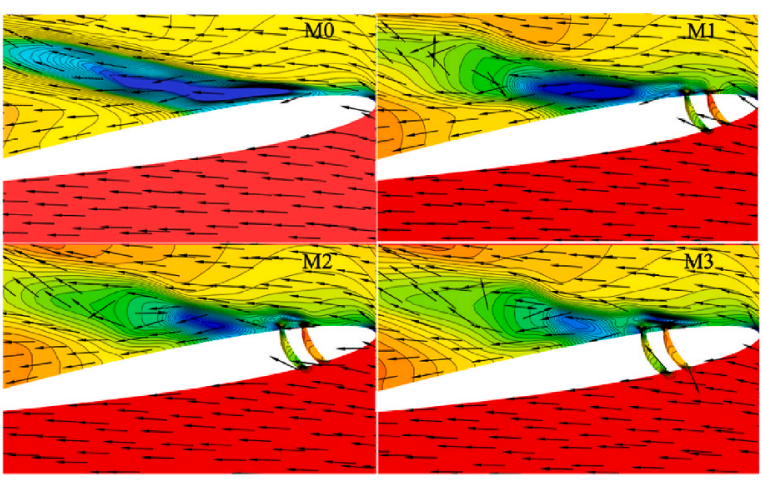

(c) $\tau=0.4$

Fig. 11. Pressure and velocity vector distributions on $Y Z$ plane $\left(V_{\infty}=10 \mathrm{~m} / \mathrm{s}\right)$.

parameters associated with the DC hole effect, such as the size of hole and the number of holes. Moreover, the effects of the DC hole on the cavitation performance and the noise production of hydrofoils should also be studied deeply.

\section{CRediT authorship contribution statement}

Yadong Huang: Writing and methology. Desheng Zhang: Supervision. Fei Wang: Calculation. Guangjian Zhang: Data processing. B.P. M. (Bart) van Esch: Writing revision.

\section{Declaration of competing interest}

The authors declare that they have no known competing financial interests or personal relationships that could have appeared to influence the work reported in this paper.

\section{Acknowledgments}

This work was financially supported by the National Natural Science Foundation of China (Grant Nos. 51776087 and 51979125) and the Equipment Pre-Research Fund Project (Grant No. 8151440002).. 


\section{References}

Amini, A., Reclari, M., Sano, T., Iino, M., Farhat, M., 2019. Suppressing tip vortex cavitation by winglets. Exp. Fluid 60 (11), 159.

Arolla, S.K., Durbin, P.A., 2014. A rotation/curvature correction for turbulence models for applied CFD. Progr. Comput. Fluid Dynam. Int. J. 14 (6), 341-351.

Bai, X., Cheng, H., Ji, B., Long, X., 2018. Large eddy simulation of tip leakage cavitating flow focusing on cavitation-vortex interaction with Cartesian cut-cell mesh method. J. Hydrodyn. 30 (4), 750-753.

Chang, N., Ganesh, H., Yakushiji, R., Ceccio, S.L., 2011. Tip vortex cavitation suppression by active mass injection. J. Fluid Eng. 133 (11).

Cheng, H., Long, X., Ji, B., Peng, X., Farhat, M., 2019. LES investigation of the influence of cavitation on flow patterns in a confined tip-leakage flow. Ocean Eng. 186, 106115.

Cheng, H.Y., Bai, X.R., Long, X.P., Ji, B., Peng, X.X., Farhat, M., 2020. Large eddy simulation of the tip-leakage cavitating flow with an insight on how cavitation influences vorticity and turbulence. Appl. Math. Model. 77, 788-809.

Decaix, J., Balarac, G., Dreyer, M., Farhat, M., Münch, C., 2015. RANS and LES computations of the tip-leakage vortex for different gap widths. J. Turbul. 16 (4), 309-341.

Decaix, J., Balarac, G., Münch, C., 2016. Rans computations of a cavitating tip vortex. In: Gourbesville, P., Cunge, J.A., Caignaert, G. (Eds.), Advances in Hydroinformatics. Springer Singapore, Singapore, pp. 519-529.

Decaix, J., Dreyer, M., Balarac, G., Farhat, M., Münch, C., 2018. RANS computations of a confined cavitating tip-leakage vortex. Eur. J. Mech. B Fluid 67, 198-210.

Dreyer, M., Decaix, J., Münch-Alligné, C., Farhat, M., 2014a. Mind the gap - tip leakage vortex in axial turbines. IOP Conf. Ser. Earth Environ. Sci. 22 (5).

Dreyer, M., Decaix, J., Münch-Alligné, C., Farhat, M., 2014b. Mind the gap: a new insight into the tip leakage vortex using stereo-PIV. Exp. Fluid 55 (11), 1849.

Fei, Z., Zhang, R., Xu, H., Mu, T., 2019. Numerical analysis of the groove effect on the tip leakage vortex cavitating flow. Proc. IME J. Power Energy 234 (6), 836-847.

Gopalan, S., Katz, J., Liu, H.L., 2002. Effect of gap size on tip leakage cavitation inception, associated noise and flow structure. J. Fluid Eng. 124 (4), 994-1004.

Guo, Q., Zhou, L., Wang, Z., 2016. Numerical evaluation of the clearance geometries effect on the flow field and performance of a hydrofoil. Renew. Energy 99, 390-397.

Guo, Q., Zhou, L., Wang, Z., Liu, M., Cheng, H., 2018. Numerical simulation for the tip leakage vortex cavitation. Ocean Eng. 151, 71-81.

Guo, Q., Huang, X., Qiu, B., 2019. Numerical investigation of the blade tip leakage vortex cavitation in a waterjet pump. Ocean Eng. 187, 8.

Ji, B., Luo, X., Wu, Y., Peng, X., Duan, Y., 2013. Numerical analysis of unsteady cavitating turbulent flow and shedding horse-shoe vortex structure around a twisted hydrofoil. Int. J. Multiphas. Flow 51, 33-43.

Kim, M.C., Chun, H.H., 2007. Experimental investigation into the performance of the axial-flow-type waterjet according to the variation of impeller tip clearance. Ocean Eng. 34 (2), 275-283.

Lei, T., Zhifeng, X., Yabin, L., Yue, H., Yun, X., 2017. Influence of T-shape tip clearance on performance of a mixed-flow pump. Proc. IME J. Power Energy 232 (4), 386-396.

Li, D., Wang, H., Qin, Y., Han, L., Wei, X., Qin, D., 2017. Entropy production analysis of hysteresis characteristic of a pump-turbine model. Energy Convers. Manag. 149, 175-191.

Liu, Y., Tan, L., 2018. Method of C groove on vortex suppression and energy performance improvement for a NACA0009 hydrofoil with tip clearance in tidal energy. Energy $155,448-461$.
Liu, Y., Tan, L., 2020a. Influence of C groove on suppressing vortex and cavitation for a NACA0009 hydrofoil with tip clearance in tidal energy. Renew. Energy 148, 907-922.

Liu, Y., Tan, L., 2020b. Method of T shape tip on energy improvement of a hydrofoil with tip clearance in tidal energy. Renew. Energy 149, 42-54.

Liu, Y., Han, Y., Tan, L., Wang, Y., 2020. Blade rotation angle on energy performance and tip leakage vortex in a mixed flow pump as turbine at pump mode. Energy 206, 118084.

Luo, Y., Wang, Z., Liu, X., Xiao, Y., Chen, C., Wang, H., et al., 2015. Numerical prediction of pressure pulsation for a low head bidirectional tidal bulb turbine. Energy 89, $730-738$.

Menter, F.R., 2009. Review of the shear-stress transport turbulence model experience from an industrial perspective. Int. J. Comput. Fluid Dynam. 23 (4), 305-316.

Pogorelov, A., Meinke, M., Schröder, W., 2016. Effects of tip-gap width on the flow field in an axial fan. Int. J. Heat Fluid Flow 61, 466-481.

Prasad, D.D., Ahmed, M.R., Lee, Y.-H., 2014. Flow and performance characteristics of a direct drive turbine for wave power generation. Ocean Eng. 81, 39-49.

Smirnov, P.E., Menter, F.R., 2009. Sensitization of the SST turbulence model to rotation and curvature by applying the Spalart-Shur correction term. J. Turbomach. 131 (4).

Souri, M., Mojra, A., 2021. A nexus between active and passive control methods for reduction of aerodynamic noise of circular cylinder. Int. J. Mech. Sci. 200, 106446.

Tan, D., Li, Y., Wilkes, I., Vagnoni, E., Miorini, R.L., Katz, J., 2015. Experimental investigation of the role of large scale cavitating vortical structures in performance breakdown of an axial waterjet pump. J. Fluid Eng. 137 (11).

Timoshevskiy, M.V., Zapryagaev II, Pervunin, K.S., Maltsev, L.I., Markovich, D.M., Hanjalić, K., 2018. Manipulating cavitation by a wall jet: experiments on a 2D hydrofoil. Int. J. Multiphas. Flow 99, 312-328.

Wu, H., Tan, D., Miorini, R.L., Katz, J., 2011. Three-dimensional flow structures and associated turbulence in the tip region of a waterjet pump rotor blade. Exp. Fluid 51 (6), 1721-1737.

Xi, S., Desheng, Z., Bin, X., Weidong, S., van Esch, B.P.M., 2021. Experimental and numerical investigation on the effect of tip leakage vortex induced cavitating flow on pressure fluctuation in an axial flow pump. Renew. Energy 163, 1195-1209.

Xiao, X., McCarter, A.A., Lakshminarayana, B., 2001. Tip clearance effects in a turbine rotor: Part I-pressure field and loss. J. Turbomach. 123 (2), 296-304.

You, D., Wang, M., Moin, P., Mittal, R., 2006. Effects of tip-gap size on the tip-leakage flow in a turbomachinery cascade. Phys. Fluids 18 (10), 14.

Yu, H., Zhang, Z., Hua, H., 2019. Numerical investigation of tip clearance effects on propulsion performance and pressure fluctuation of a pump-jet propulsor. Ocean Eng. 192, 106500.

Zarei, A., Ashouri, A., Hashemi, S., Bushehri, S., Izadpanah, E., Amini, Y., 2020. Experimental and numerical study of hydrodynamic performance of remotely operated vehicle. Ocean Eng. 212, 107612.

Zhang, D., Shi, W., Pan, D., Dubuisson, M., 2015a. Numerical and experimental investigation of tip leakage vortex cavitation patterns and mechanisms in an axial flow pump. J. Fluid Eng. 137 (12), 14.

Zhang, D., Shi, L., Shi, W., Zhao, R., Wang, H., van Esch, B.P.M., 2015b. Numerical analysis of unsteady tip leakage vortex cavitation cloud and unstable suction-sideperpendicular cavitating vortices in an axial flow pump. Int. J. Multiphas. Flow 77, 244-259.

Zhao, Y., Wang, G., Jiang, Y., Huang, B., 2016. Numerical analysis of developed tip leakage cavitating flows using a new transport-based model. Int. Commun. Heat Mass Tran. 78, 39-47. 